\title{
A Unidirectional Hybrid HVDC Transmission System Based on Diode Rectifier and Full-bridge MMC
}

\author{
Rui Li, Member, IEEE and Lie Xu, Senior Member, IEEE
}

\begin{abstract}
To reduce the cost of bulk power transmission using voltage source converter HVDC technology, a unidirectional hybrid converter is proposed, where a diode rectifier and a modular multilevel converter (MMC) based on full-bridge (FB) submodules are connected in series on DC side. The FB-MMC controls its DC voltage to regulate the transmitted power. The majority of the power transmission is via the diode rectifier considering its cost and efficiency superiority and only low power rating $\mathrm{FB}-\mathrm{MMC}$ is required. A thyristor valve is equipped at the DC side of the FB-MMC to prevent potential overcharge of the FB submodules during DC faults. Compared to conventional MMCs, losses can potentially be reduced by around $20 \%$. An active power controller is proposed to regulate the DC voltage of the FB-MMC so as to control the transmitted power. With the inverter station controlling its DC terminal voltage constant, the FB-MMC increases the output DC voltage to increase the transmitted power and, vice versa. To alleviate overvoltage of the HVDC link during AC grid faults of the inverter station, a dynamic DC voltage limiter is designed to actively reduce the DC output voltage of the FBMMC. Simulation results confirm the proposed converter operation and control.
\end{abstract}

Index Terms - active power control, diode rectifier HVDC (DRHVDC), fault ride-through, HVDC transmission, full-bridge (FB) based modular multilevel converter (MMC).

\section{INTRODUCTION}

$\mathrm{H}$ igh-voltage DC (HVDC) transmission systems based on modular multilevel converters (MMCs) have developed rapidly due to their significant advantages. The most widely used MMC configuration is based on the half-bridge (HB) submodule (SM), whereas other MMC topologies have been proposed, e.g. MMCs based on the full-bridge (FB) SM [1], clamp double (CD) SM [2], and mixed SM [3], alternate-arm multilevel converters (AACs) [4], hybrid cascaded MMC [5], etc.

Diode rectifier (DR) based HVDC systems have recently received notable interest for integrating large offshore wind farms [6-8]. By replacing the MMC offshore station with diode rectifier, the volume and weight of the offshore platform can be significantly reduced. In addition, it also leads to substantial reduction in the transmission losses and the total cost, e.g. $20 \%$ and $30 \%$ respective reductions as quoted in $[6,7]$.

A voltage and frequency control of the offshore wind turbines connected with DR-HVDC system is presented in [9],

The work is supported in part by the European Union's Horizon 2020 research and innovation program under grant agreement No 691714.

R. Li and L. Xu are with the Department of Electronic and Electrical Engineering, University of Strathclyde, Glasgow, G1 1XW, UK (e-mail: rui.li@strath.ac.uk, lie.xu@strath.ac.uk). which proves that such solution is technically feasible in steady state and transients. The fault ride-through capability of DRHVDC connected with offshore wind farm is further validated in [10-13]. However, the wind turbines in DR-HVDC systems need to operate in grid forming mode to build up the offshore $\mathrm{AC}$ network and the conventional wind turbines operating on grid following mode cannot be used for the DR-HVDC systems. In addition, the $\mathrm{AC}$ voltage magnitude of the network connected to DR-HVDC has to vary in order to regulate the active power transmission.

To address this issue, various hybrid topologies have been proposed. In [14], a two-level voltage source converter (VSC) is connected in series with the DR on DC side and controls the offshore AC voltage constant to transmit the generated wind power to onshore. The two-level VSC also compensates reactive power and suppresses harmonics generated by the DR. Reference [15] proposes to connect the cascaded H-bridge (CHB) converter with the DR on AC side, which only controls the frequency of the offshore AC network while the magnitude remains uncontrolled and is intrinsically clamped by the DR. Such control is different to the conventional control of static synchronous compensators (STATCOMs) where reactive power is generated through regulation of the AC voltage magnitude. The AC filter of the DR is removed and all of the reactive power and harmonics generated by the DR are compensated by the $\mathrm{CHB}$ converter. However, the $\mathrm{CHB}$ converter needs to be rated over $30 \%$ of the power rating of the DR-HVDC link, leading to high capital cost. In [16], the DR and $\mathrm{MMC}$ are connected in parallel on AC sides to optimize the power flow distribution between these two HVDC links and improve availability of the parallel connected HVDC systems during faults. The MMC is connected in parallel with the DR on both AC and DC sides in [17] to energize the offshore AC grid and wind turbines during start-up and control the offshore frequency during normal operation. However, the parallel connected VSC needs to be rated at the nominal DC voltage of the DR. In [18], cascaded FB SMs are connected at the VSC DC output to reduce the DC voltage rating of the parallel connected VSC. However, LC filter is required to constrain high frequency circulating currents between the VSC and DR.

The DR-HVDC systems in the aforementioned references are used for offshore wind energy transmission, where the offshore network is formed either by wind turbines [9-13] or by additional converters [14, 15, 18], and the AC voltage magnitude can be varied by the system. This paper aims to extend the DR concept to onshore application, where the AC voltage is independent of the transmission system, considering that the power flow of HVDC systems often has unidirectional characteristics when transmitting power from large power plants to load centers $[19,20]$. The main contributions are: 
- A hybrid HVDC converter is proposed, where a high power rating DR is connected with a low power rating FB-MMC in series on the DC side, whilst a thyristor valve is in parallel with the FB-MMC for DC fault protection. The majority of the power transmission is via the DR considering its low cost and high efficiency while the FB-MMC is used to control the transmitted power by regulating the overall DC voltage generated by the two converters.

- A simple power-DC voltage $\left(P-V_{d c}\right)$ control scheme is proposed to regulate the DC voltage of the FB-MMC so as to control the transmitted power of the HVDC link. A dynamic DC voltage limiter is introduced to actively reduce the DC output voltage of the FB-MMC to alleviate DC overvoltage of the HVDC link during AC grid faults of the inverter station.

The paper is organized as follows. The layout of the hybrid HVDC converter and its control strategy are proposed in Section II. In Section III, the design principles of the proposed topology and its efficiency superiority as well as economic benefits are presented. The proposed topology and its control strategy are assessed in Section IV and finally, Section V draws conclusions.

\section{PRoposed Hybrid HVDC SYSTEM BASEd ON Diode RECTIFIER AND FB-MMC}

\section{A. Converter Topology}

Fig. 1 shows a generic version of the proposed hybrid HVDC converter comprising a diode rectifier bridge and FB SM based MMC (DFB-MMC). As seen, its main power stage consists of series connection of a high power 12-pulse DR bridge and a low power FB-MMC on their DC sides, while their AC sides are connected in parallel through interface transformers. Filters are connected on the DR AC side for reactive power compensation and harmonic suppression [6, 21]. Thyristor valve $S_{1}$ is connected in parallel with the FB-MMC on its DC side for DC fault protection, as will be detailed later. The DR and FB-MMC are designed such that the majority of the transmitted power is through the DR taking the advantage of its lower cost and high efficiency compared to MMCs while the low power rating FBMMC is used to control the transmitted power of the whole hybrid HVDC system by regulating its DC voltage.

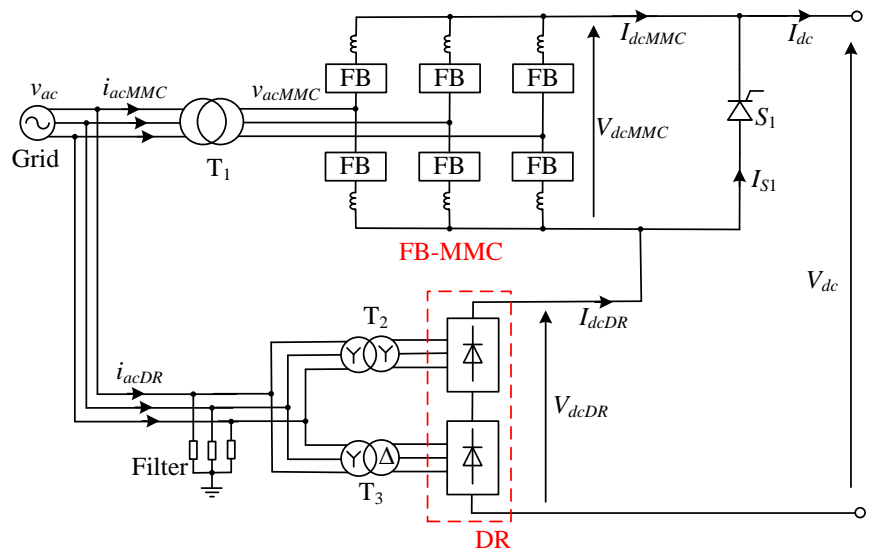

Fig. 1. Proposed hybrid HVDC converter based on diode rectifier and fullbridge MMC.
During normal operation, the thyristor valve $S_{1}$ is off and the FB-MMC is connected in-series with the DR to transmit power. The voltage across $S_{1}$ equals to the nominal FB-MMC DC voltage $V_{d c M M C}$.

In the event of DC faults, the FB-MMC is quickly blocked after fault detection, which then provides negative blocking voltage to its $\mathrm{AC}$ side to fast extinguish $\mathrm{AC}$ fault current. However, if the thyristor valve $S_{1}$ is not activated, the fault current fed from the DR AC side will flow through and charge the SMs of the FB-MMC, as indicated by the dashed lines in Fig. 2. This leads to overvoltage of the FB SM capacitors. Thus, the thyristor valve $S_{1}$ is activated in addition to the blocking of the FB-MMC after fault detection as aforementioned. Therefore, all the DC fault current from the DR $I_{d c D R}$ flows through the thyristor $S_{1}$ and the FB-MMC is bypassed, as illustrated by the solid lines in Fig. 2. The AC circuit breakers (ACCBs) equipped at the AC terminals of the DR and FBMMC then open for fault protection. The power transmission of the HVDC station is interrupted during DC faults, in a similar way as systems based on conventional HB-MMCs protected by ACCBs $[22,23]$. Such protection arrangement is much cheaper than those using fast acting DC circuit breakers but may not be preferred for multi-terminal HVDC systems due to its relatively slow action.

Due to the fast protection response, the IGBTs in the FBMMC can be quickly blocked and the contribution of DC fault current from SM capacitor discharging is thus limited. Similar to conventional HB-MMCs, the fault currents of the proposed converter are mainly fed from the grid through the DR.

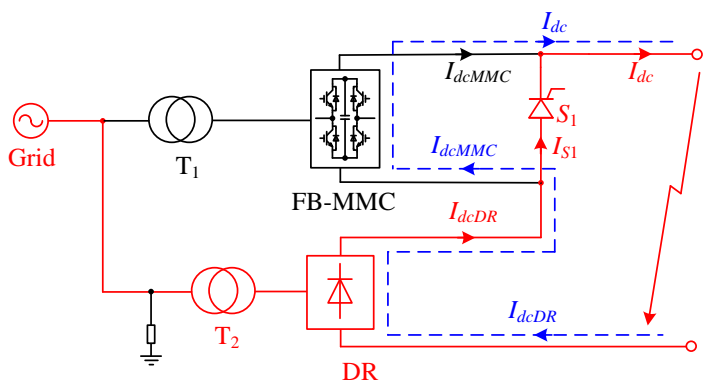

Fig. 2. Single-phase illustration of fault current path during DC faults.

\section{B. Operation Principle}

The HVDC link based on the proposed topology is illustrated in Fig. 3, where the DFB-MMC and conventional HB-MMC are adopted as the rectifier and inverter stations, respectively. The proposed DFB-MMC controls the transmitted power while the HB-MMC of the inverter station operates on DC voltage control mode and regulates its DC terminal voltage at the rated value.

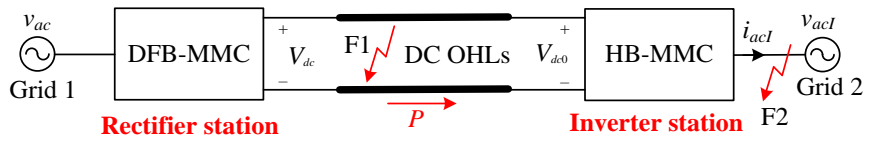

Fig. 3. HVDC link based on the proposed DFB-MMC.

Fig. 4 illustrates the equivalent circuit of the HVDC link shown in Fig. 3. During normal operation, the HB-MMC controls its DC terminal voltage at the rated value $V_{d c 0}$ and is thus represented by a DC voltage source $V_{d c 0}$. To calculate the 
steady state transmitted power, the DC transmission lines are simplified as a resistor $R_{d c}$ in the equivalent circuit. The transmitted power of the inverter station is thus expressed as

$$
P=V_{d c 0} I_{d c}=V_{d c 0} \frac{V_{d c}-V_{d c 0}}{R_{d c}}=\frac{V_{d c 0} V_{d c}-V_{d c 0}^{2}}{R_{d c}}
$$

where $I_{d c}$ and $V_{d c}$ are the DC current and voltage of the DFBMMC, respectively.

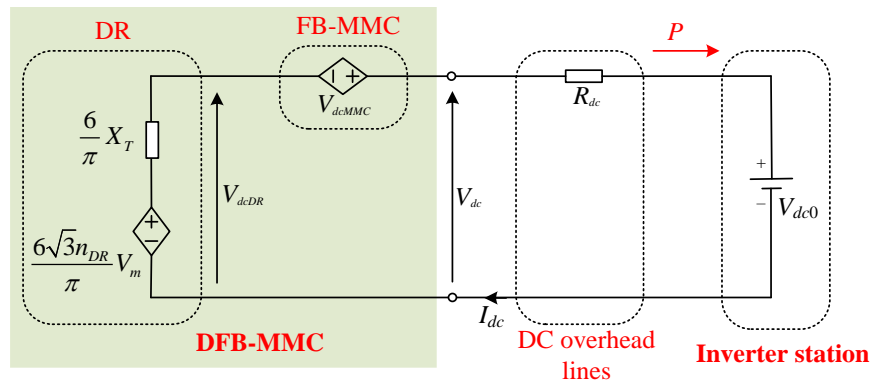

Fig. 4. Equivalent circuit of the HVDC link based on the proposed DFB-MMC.

Due to the series connection, the DC voltage of the DFBMMC is the sum of the DR DC voltage $V_{d c D R}$ and the FB-MMC DC voltage $V_{d c M M C}$ :

$$
V_{d c}=V_{d c D R}+V_{d c M M C} .
$$

Substituting (2) into (1), the active power $P$ is rewritten as:

$$
P=\frac{V_{d c 0}\left(V_{d c D R}+V_{d c M M C}\right)-V_{d c 0}^{2}}{R_{d c}} .
$$

The DC voltage produced by the DR is depicted as [12]:

$$
V_{d c D R}=\frac{6}{\pi}\left(\sqrt{3} n_{D R} V_{m}-X_{T} I_{d c}\right)=\frac{6}{\pi}\left(\sqrt{3} n_{D R} V_{m}-X_{T} \frac{P}{V_{d c 0}}\right)
$$

where $n_{D R}$ is the DR transformer ratio, $X_{T}$ is the leakage reactance of the DR transformer, and $V_{m}$ is the phase voltage amplitude of the AC grid. From (3) and (4), the active power $P$ is rewritten as:

$$
P=\frac{\pi V_{d c 0}}{\pi R_{d c}+6 X_{T}} V_{d c M M C}+\frac{6 \sqrt{3} n_{D R} V_{m} V_{d c 0}-\pi V_{d c 0}{ }^{2}}{\pi R_{d c}+6 X_{T}} .
$$

As depicted by (5), the transmitted power $P$ of the HVDC link can be controlled by regulating the DC voltage $V_{d c} M{ }_{1}$ of the FB-MMC. The detailed design considering the relative power ratings of the DR and FB-MMC will be given in Section III.

\section{Control Strategy}

The control strategy of the proposed topology, including active power regulation and overvoltage alleviation during AC grid faults of the inverter station, is presented in this subsection.

1) Active power regulation

A simple power-DC voltage $\left(P-V_{d c}\right)$ control scheme is proposed to regulate the DC voltage of the FB-MMC so as to control the transmitted power of the DFB-MMC according to (5).

As shown in Fig. 5 (a), the error between the power reference $P^{*}$ and the measured actual power $P$ of the DFB-MMC is fed to a PI control and its output sets the DC voltage reference $V_{d c M M C}^{*}$ of the FB-MMC. To increase the power $P$ of the DFB-MMC, the active power controller increases the output DC voltage $V_{d c M M C}$ and, vice versa. The DC voltage of the FB-MMC is thus varied to follow the power order $P^{*}$. The active power $P$ is measured as the product of the DC voltage $V_{d c}$ and DC current $I_{d c}$ of the DFB-MMC and a low-pass filter (LPF) is used to take out the high-order harmonics of the DC power $P$.

As illustrated in Fig. 5 (b), the DC voltage reference $V_{d c M M C}^{*}$ set by the active power controller is fed to the DC voltage control loop to regulate the $d$-axis current reference $i_{d}^{*}$, considering the sign of $V_{d c M M C}^{*}$. The current controller generates the required $\mathrm{AC}$ voltage $v_{c}$ to be produced by the FBMMC. The upper and lower arm voltage references are then generated considering the requirement from the circulating current controller, which are fed to the nearest level modulation (NLM) and SM capacitor voltage balancing control block to finally output the gating signals for the SMs.

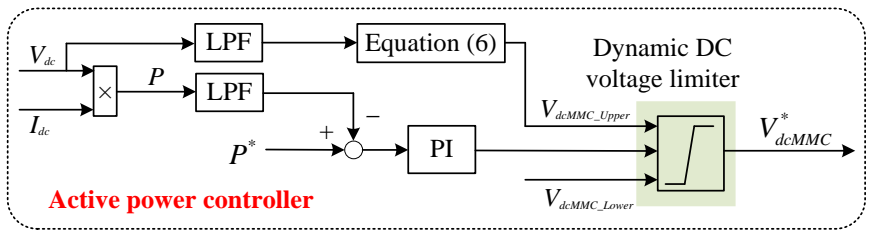

(a)

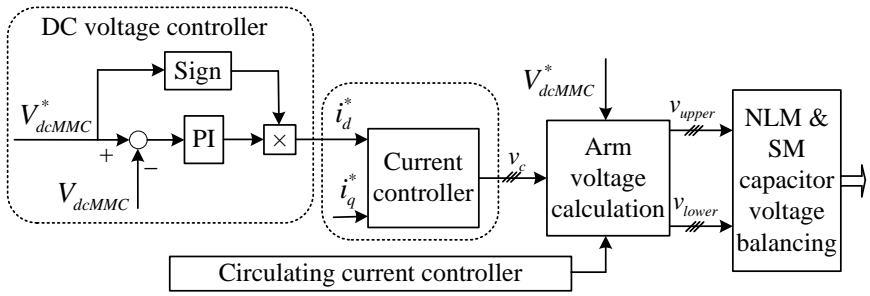

(b)

Fig. 5. Control strategy of the proposed DFB-MMC: (a) active power controller and (b) other control blocks.

2) Overvoltage alleviation during AC grid faults of inverter station

In the event of $\mathrm{AC}$ grid faults of the inverter station, the $\mathrm{HB}$ MMC of the inverter station will operate in current limiting mode due to sudden drop of the AC grid voltage, and the active power output capability of the inverter significantly decreases. If the power transmitting from the rectifier station continues, the power unbalance between the rectifier and inverter stations can lead to overvoltage of the HVDC link.

To alleviate such overvoltage, a dynamic DC voltage limiter is proposed to enable the FB-MMC to generate negative DC voltage by limiting the output of the active power controller in the introduced $P-V_{d c}$ control scheme, as illustrated in Fig. 5. The lower limit $V_{d c M M C_{-} L o w e r}$ is set at $-V_{d c M M C 0}$ while the upper limit $V_{d c M M C_{-} \text {Upper }}$ is dependent on the DFB-MMC DC voltage $V_{d c}$, as described as

$$
V_{d c M M C_{-} \text {upper }}=\left\{\begin{array}{lc}
V_{d c M M C 0}, & V_{d c} \leq V_{d c_{-} \text {thres }} \\
V_{d c_{-} \text {thres }}-V_{d c}, & V_{d c}>V_{d c_{-} \text {thres }}
\end{array}\right.
$$

where $V_{d c M M C 0}$ is the rated DC voltage of the FB-MMC and $V_{d c_{\text {t thres }}}$ is the overvoltage threshold of the DFB-MMC and is set at $1.05 V_{d c 0}$ in this paper. A low pass filter is used to take out the high-order harmonics of the DFB-MMC DC voltage $V_{d c}$ in (6). During normal operation, $V_{d c}$ is below is the overvoltage threshold $V_{d c_{-} t h r e s}$ and the upper limit of the DC voltage reference $V_{d c M M C_{-} \text {upper }}$ is set at the rated DC voltage $V_{d c M M C 0}$ of the FB-MMC. In the event of AC grid faults of the inverter 

is subject to Institution of Electrical and Electronic Engineering Copyright. The copy of record is available at IEEE Xplore Digital Library.

station, the power transmission is interrupted and the active power PI controller saturates to try to increase the DC voltage to resume power transmission. Due to the power surplus, the DC voltage $V_{d c}$ of the HVDC link increases and once $V_{d c}$ exceeds the threshold $V_{d c_{-} \text {thres }}$, the upper limit $V_{d c M M C_{-} \text {upper }}$ is limited to $V_{d c_{-} \text {thres }}-V_{d c}$. Thus, the DC voltage reference $V_{d c M M C}^{*}$ of the FB-MMC is set at $V_{d c_{-} \text {thres }}-V_{d c}$ by the dynamic limiter and the FB-MMC outputs negative DC voltage to actively reduce the potential overvoltage of HVDC link. After fault isolation, the DC voltage of the HVDC link restores and the DC voltage reference $V_{d c м м C}^{*}$ is set by the active power PI controller to automatically restore power transmission.

\section{Design CONSIDERATIONS OF THE PROPOSED TOPOLOGY}

The design of the proposed hybrid HVDC converter is carried out in this section, considering the DC voltage and SM capacitance requirements of the FB-MMC.

\section{A. DC Voltage Requirements of FB-MMCs}

The DC voltage $V_{d c}$ of the DFB-MMC is expressed as:

$$
V_{d c}=V_{d c 0}+R_{d c} I_{d c}=V_{d c 0}+R_{d c} \frac{P}{V_{d c 0}} .
$$

From (4) and (7), the DC voltage of the FB-MMC is derived as

$$
V_{d c M M C}=V_{d c}-V_{d c D R}=V_{d c 0}+\left(R_{d c}+\frac{6}{\pi} X_{T}\right) \frac{P}{V_{d c 0}}-\frac{6}{\pi} \sqrt{3} n_{D R} V_{m} .
$$

With the variation of grid voltage, the DFB-MMC needs to be capable of regulating the transmitted power from zero to the rated value $P_{0}$, by regulating the DC voltage $V_{d c M M C}$ of the FBMMC. The maximum DC voltage $V_{d c M M C \max }$ of the FB-MMC is required when the grid voltage $V_{m}$ is at the lower limit of $V_{m 0^{-}}$ $\Delta V_{m}$ while transmitting the rated power $P_{0}$, where $V_{m 0}$ and $\Delta V_{m}$ are the rated value and variation of AC grid voltage $V_{m}$. From (8), $V_{d c M M C \max }$ is expressed as

$$
V_{d c M M C \max }=V_{d c 0}+\left(R_{d c}+\frac{6}{\pi} X_{T}\right) \frac{P_{0}}{V_{d c 0}}-\frac{6}{\pi} \sqrt{3} n_{D R}\left(V_{m 0}-\Delta V_{m}\right) .
$$

The required minimum DC voltage $V_{d c M M C \min }$ is defined when the grid voltage reaches the peak of $V_{m 0}+\Delta V_{m}$ while the transmitted power $P$ is zero, where the FB-MMC needs to output minimum voltage (negative) to suppress the transmitted power to zero. According to (8), $V_{d c M M C \min }$ is derived as

$$
V_{d c M M C \min }=V_{d c 0}-\frac{6 \sqrt{3} n_{D R}\left(V_{m 0}+\Delta V_{m}\right)}{\pi} .
$$

To reduce the power rating of the FB-MMC, its negative voltage generating capability is utilized and thus the sum of the maximum and minimum voltages is zero:

$$
V_{d c M M C \max }+V_{d c M M C \min }=0 \text {. }
$$

From (9)-(11), the ratio $n_{D R}$ of the DR transformer is governed by

$$
n_{D R}=\frac{2 \sqrt{3} \pi V_{d c 0}^{2}+\sqrt{3}\left(\pi R_{d c}+6 X_{T}\right) P_{0}}{36 V_{d c 0} V_{m 0}} .
$$

Setting the DR interface transformer ratio $n_{D R}$ according to (12) ensures that the sum of the required maximum and minimum DC voltages of the FB-MMC is zero to minimize its power rating.

From (9), (10) and (12), the required maximum and minimum DC voltages of the FB-MMC are
$V_{d c M M C \max }=-V_{d c M M C \text { min }}=\frac{V_{d c 0}}{V_{m 0}} \Delta V_{m}+\frac{P_{0}}{V_{d c 0}}\left(\frac{3 X_{T}}{\pi}+\frac{R_{d c}}{2}\right)\left(1+\frac{\Delta V_{m}}{V_{m 0}}\right)(13)$

The rated DC voltage of the FB-MMC is designed to ensure the maximum and minimum DC voltages as depicted by (13) can be met, considering $10 \%$ overrating, as

$$
V_{d c M M C 0}=1.1 V_{d c M M C \max }=-1.1 V_{d c M M C \min } \text {. }
$$

From (13) and (14), the ratio between the rated FB-MMC DC voltage and the rated DFB-MMC DC voltage (i.e. $\left.V_{d c M M C 0} / V_{d c 0}\right)$ is shown in Fig. 6. The ratio $V_{d c M M C 0} / V_{d c 0}$ is directly proportional to the AC grid voltage variation of $\Delta V_{m} / V_{m 0}$ and is $9.3 \%, 12.7 \%$ and $15 \%$ respectively when $\Delta V_{m} / V_{m 0}$ is equal to $5 \%, 8 \%$ and $10 \%$. This indicates the power rating of the $\mathrm{FB}-\mathrm{MMC}$ is dependent on the grid variation and is $15 \%$ of that of the DFB-MMC (i.e. $15 \% P_{0}$ ) when $10 \%$ grid voltage variation (i.e. $\Delta V_{m} / V_{m 0}=10 \%$ ) is considered. Thus, only low power rating of the FB-MMC is required for the proposed topology while the majority power is transmitted via the costeffective and efficient diode rectifier. Different to the FB-MMC DC voltage $V_{d c M}$ c , the transformer ratio $n_{D R}$ is independent on the grid variation $\Delta V_{m}$, as depicted by (12).

Considering the relatively lower current rating of IGBTs (adopted in the FB-MMC) than that of diodes (adopted in the DR), parallel connection of IGBTs as commonly used in HBMMC systems [24, 25] can be adopted to increase the overall current capacity of the FB-MMC to match that of the diodes.

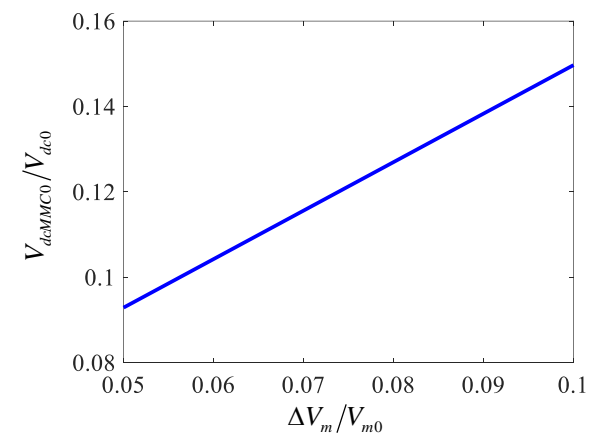

Fig. 6. Ratio between the rated FB-MMC DC voltage and the rated DFB-MMC DC voltage (i.e. $V_{d c M M C 0} / V_{d c 0}$ ) with the variation of AC grid voltage.

\section{B. SM Capacitance Requirements}

Different from conventional FB-MMC, the SM capacitor voltage variation of the FB-MMC in the proposed arrangement largely depends on the $\mathrm{AC}$ grid voltage variation and thus the required SM capacitance is presented in this subsection.

The arm voltage of the proposed DFB-MMC is expressed as

$$
v_{\text {arm }}=\frac{1}{2} V_{d c M M C}-n_{M M C}\left(V_{m 0}+\Delta V_{m}\right) \sin (\omega t)
$$

where $n_{M M C}$ is the FB-MMC interface transformer ratio and $\omega$ is the angular frequency of the $\mathrm{AC}$ grid. Assuming the converter is lossless, the AC power of the FB-MMC equals its DC power:

$$
\frac{3}{2} n_{M M C} I_{m M M C}\left(V_{m 0}+\Delta V_{m}\right)=\frac{P}{V_{d c 0}} V_{d c M M C}
$$

where $I_{m M M C}$ is the converter-side peak current of the FB-MMC. From (16), $I_{m M M C}$ is obtained as

$$
I_{m M M C}=\frac{2 V_{d c M M C} P}{3 n_{M M C} V_{d c 0}\left(V_{m 0}+\Delta V_{m}\right)} .
$$


This paper is a post-print of a paper submitted to and accepted for publication in IEEE Journal of Emerging and Selected Topics in Power Electronics and is subject to Institution of Electrical and Electronic Engineering Copyright. The copy of record is available at IEEE Xplore Digital Library.

According to (17), the arm current is derived as

$$
i_{a r m}=\frac{P}{3 V_{d c 0}}+\frac{V_{d c M M C} P}{3 n_{M M C} V_{d c 0}\left(V_{m 0}+\Delta V_{m}\right)} \sin (\omega t-\varphi)(
$$

where $\varphi$ is the phase angle. From (15) and (18), integrating the product of the arm voltage and current yields the arm energy variations as

$$
\begin{aligned}
& \Delta E_{a r m}(\omega t)=\frac{1}{\omega} \int_{0}^{\omega t} v_{a r m} i_{a r m} d(\omega t) \\
& =-\frac{V_{d c M M C}{ }^{2} P}{6 n_{M M C} V_{d c 0} \omega\left(V_{m 0}+\Delta V_{m}\right)}[\cos (\omega t-\varphi)-\cos \varphi]+ \\
& \frac{P\left(V_{m 0}+\Delta V_{m}\right)}{3 \omega V_{d c 0}}[\cos (\omega t)-1]+ \\
& \frac{V_{d c M M C} P}{12 n_{M M C} V_{d c 0} \omega}[\sin (2 \omega t-\varphi)+\sin \varphi]
\end{aligned}
$$

As depicted by (19), the arm energy variation peaks depend on the transmitted power $P$ and the grid voltage variation ratio $\Delta V_{m} / V_{m 0}$, as shown in Fig. 7. When the grid voltage decreases to $0.9 \mathrm{pu}$ (i.e. $1+\Delta V_{m} / V_{m 0}=0.9$ ) while transmitting the rated power, the arm energy variation peak of the tested system reaches the maximum value of $320 \mathrm{~kJ}$, which defines the required SM capacitance. The corresponding SM capacitance requirement is $31 \mathrm{~kJ} / \mathrm{MVA}$, which is in agreement with the guidance value of 30 40 kJ/MVA as suggested by ABB in [26].

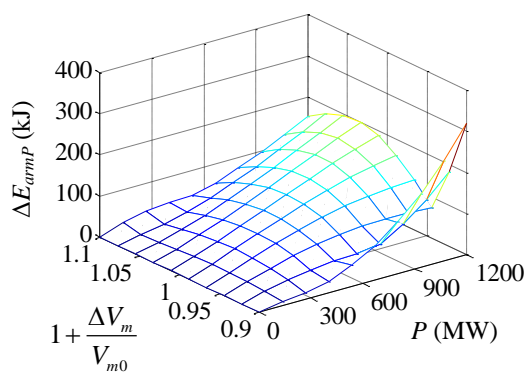

Fig. 7. Arm energy variation peak of the proposed converter with the variation of grid voltage $1+\Delta V_{m} / V_{m 0}$ and transmitted power $P$.

During normal operation, the grid voltage (i.e. $1+\Delta V_{m} / V_{m 0}$ in Fig. 7) is usually in the range of $0.95 \sim 1.05$ and the arm energy variation peak is less than the designed value of $320 \mathrm{~kJ}$. Thus, with the same SM capacitor voltage variation, the SMs of the proposed topology can be switched less frequently than that of conventional MMCs [27], leading to reduced switching losses.

\section{Comparison between the Proposed DFB-MMC and Other Alternatives}

The overall loss of the conventional HB-MMC station is typically $0.8 \%$ [28], including semiconductor valves, transformers, valve reactors, DC reactors, and auxiliary supplies, etc. The power losses of the semiconductor valves are around half of the overall loss of the station, i.e. $0.4 \%[29,30]$. The switching and conduction losses of the conventional HBMMC are $30 \%$ and $70 \%$ of the semiconductor valve power losses, respectively. The FB-MMC has similar switching losses to that of the HB-MMC but its conduction losses are doubled. The loss of the FB-MMC is thus derived as $1.08 \%$ [3, 28, 29, $31]$. Considering the DR loss of $0.5 \%[16,32]$ and the FBMMC power rating of $0.15 P_{0}$, the loss of the proposed DFB-
MMC in nominal condition is calculated as $1.08 \% \times 0.15+0.5 \% \times 0.85=0.59 \%$, being $26.6 \%$ lower than that of the conventional HB-MMC (i.e. $0.8 \%$ ).

The power losses of the semiconductor valves consist of switching and conduction losses and their ratio varies in the range of $20 \% / 80 \%$ and $40 \% / 60 \%$, depending on the adopted IGBT technology and the modulation strategy. Considering the ratio of $20 \% / 80 \%$, the loss of the proposed DFB-MMC is $25.9 \%$ lower than that of the conventional HB-MMC. Similarly, the loss is reduced by $27.4 \%$ when the ratio between switching and conduction losses is $40 \% / 60 \%$. It should be noted that the ratio between the losses of HVDC stations and the transmitted power is not constant and changes with the variation of the transmitted power and network condition. The aforementioned losses are obtained when transmitting the rated power, while for other power levels, the losses will vary [3, 28, 29, 31].

The major power is transferred through the DR in the proposed topology and only low power rating FB-MMC is required (i.e. maximum $15 \%$ of the system power rating as shown in Fig. 6). Thus, the cost of the proposed converter is substantially reduced compared to the conventional MMC, considering high efficiency of the DR. In addition, the capitalized cost associated with losses is typically in the range of $3000 \sim 5000 € / \mathrm{kW}[29,30,33,34]$ and, considering the average value of $4000 € / \mathrm{kW}$ and $26.6 \%$ loss reduction of the proposed topology, the cost is further reduced by $10 \mathrm{M} €$ if the conventional MMC rated at $1200 \mathrm{MW}$ is replaced by the proposed DFB-MMC.

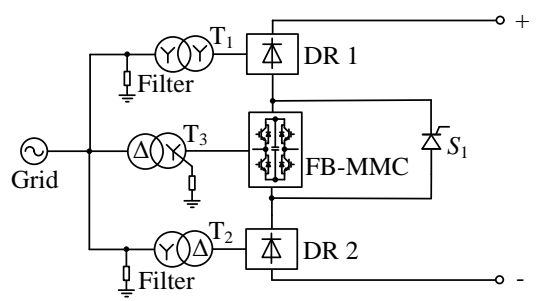

(a)

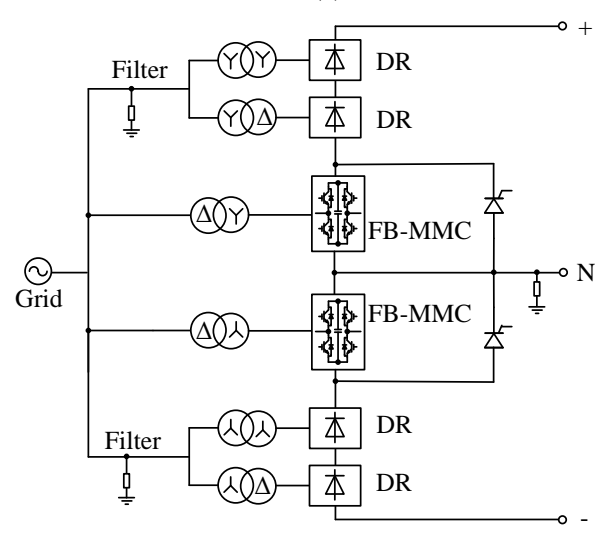

(b)

Fig. 8. Possible system configurations based on the proposed converter: (a) symmetrical monopole and (b) bipole.

Compared to conventional line-commutated converters (LCCs), the size of filters required by the DR in the proposed topology is reduced, leading to lower volume and cost $[12,35$, 36]. In addition, the FB-MMC can actively compensate reactive power and suppress harmonics generated by the DR [14], which 
further reduces the filter size of the proposed converter. Moreover, the power loss of the proposed DFB-MMC is comparable to that of the LCC rectifier $(0.59 \%$ vs. $0.63 \%$ for LCC [28, 31]).

\section{System Configuration}

This subsection provides high-level discussions of possible system configurations based on the proposed DFB-MMC, as shown in Fig. 8.

Fig. 8 (a) depicts the schematic diagram of the generic symmetrical monopole configuration. Two diode rectifiers are connected to the positive and negative DC poles, respectively, with the FB-MMC connected in series in the middle. A $\Delta / Y$ transformer with converter-side high impedance grounding is taken as an example [37-39].

Fig. 8 (b) display a generic representation of the bipole configuration with metallic return. In the event of one pole outage, the healthy pole can continue operating with the neutral line, similar to conventional MMC based bipole HVDC system arrangement.

TABLE I

Nominal parameters of the tested system.

\begin{tabular}{|c|c|c|}
\hline \multicolumn{2}{|c|}{ PARAMETER } & Nominal Value \\
\hline \multirow{3}{*}{ Grid } & Voltage & $400 \mathrm{kV}$ \\
\hline & Short circuit level & $10 \mathrm{GW}$ \\
\hline & $\mathrm{X} / \mathrm{R}$ ratio & 14 \\
\hline \multicolumn{2}{|c|}{ Power rating $P_{0}$} & $1200 \mathrm{MW}$ \\
\hline \multicolumn{2}{|c|}{ Overall DC voltage } & $\pm 550 \mathrm{kV}$ \\
\hline \multirow{8}{*}{ FB-MMC } & DC-link voltage $V_{d c M M C 0}$ & $165 \mathrm{kV}$ \\
\hline & Power rating & $180 \mathrm{MW}$ \\
\hline & SM number per arm & 80 \\
\hline & SM capacitor voltage & $2.06 \mathrm{kV}$ \\
\hline & SM capacitance & $5.4 \mathrm{mF}$ \\
\hline & Arm inductance & $0.1 \mathrm{pu}$ \\
\hline & $\begin{array}{l}\text { Grid- and converter-side } \\
\text { voltages of transformer }\end{array}$ & $400 \mathrm{kV} / 84 \mathrm{kV}$ \\
\hline & $\begin{array}{l}\text { Transformer leakage } \\
\text { inductance }\end{array}$ & $0.15 \mathrm{pu}$ \\
\hline \multirow{2}{*}{$\begin{array}{l}\text { 12-pulse } \\
\text { diode rectifier }\end{array}$} & $\begin{array}{l}\text { Grid- and converter-side } \\
\text { voltages of transformer }\end{array}$ & $400 \mathrm{kV} / 422 \mathrm{kV}$ \\
\hline & $\begin{array}{l}\text { Transformer leakage } \\
\text { inductance }\end{array}$ & $0.15 \mathrm{pu}$ \\
\hline \multirow{2}{*}{$\begin{array}{l}\text { DC overhead } \\
\text { line }\end{array}$} & Length & $150 \mathrm{~km}$ \\
\hline & $\begin{array}{l}R, L \text { and } C \text { of DC OHLs } \\
{[40]}\end{array}$ & $\begin{array}{l}10 \mathrm{~m} \Omega / \mathrm{km}, 0.9 \mathrm{mH} / \mathrm{km}, \\
0.02 \mu \mathrm{F} / \mathrm{km}\end{array}$ \\
\hline
\end{tabular}

\section{Simulation Results}

The proposed topology and control scheme are assessed using the HVDC link shown in Fig. 3 in Matlab/Simulink environment, considering normal operation and faults. The symmetrical monopole configuration as illustrated in Fig. 8 (a) is adopted, where the DC voltage and the length of the overhead lines (OHLs) are $\pm 550 \mathrm{kV}$ and $150 \mathrm{~km}$, respectively. These are comparable to the DC voltage of $\pm 500 \mathrm{kV}$ in the Zhangbei fourterminal HVDC project with OHLs of $66 \mathrm{~km}, 126 \mathrm{~km}, 219 \mathrm{~km}$ and $227 \mathrm{~km}$ [41]. In addition to OHLs, the proposed converter is also applicable to cable schemes. To improve the simulation accuracy, each OHL is modeled as 10 pi sections with detailed parameters listed in Table I $[42,43]$. The proposed DFB-MMC is adopted as the rectifier station and operates on power control mode, whilst the HB-MMC of the inverter station controls its DC terminal voltage constant [3]. The FB-MMC and HB-MMC are represented by detailed submodule-based switching function model [44] while the DR is represented by detailed switching model. The parameters of the tested DFB-MMC are listed in Table I. The ACCB is modelled with an opening delay time of $60 \mathrm{~ms}$ and can only be opened at current zero crossing. DC reactors of $50 \mathrm{mH}$ are connected at the DC terminals of the proposed converter to limit the fault current rising rate, which is similar to the conventional HB-MMC based systems [22, 41].

\section{A. Normal Operation}

Two worst scenarios, i.e. the grid voltage of 0.9 and $1.1 \mathrm{pu}$, are considered in this subsection to test the power regulation capability of the proposed HVDC converter.

1) Low grid voltage of $0.9 \mathrm{pu}$

Initially, the grid voltage is at the lower limit and the power order of the rectifier station is set at zero. The output voltage of the FB-MMC is zero and the DR is reversely blocked due to the low AC grid voltage, leading to zero transmitted power of the DFB-MMC, as seen in Fig. 9 (b), (d) and (f). The DC voltage of DFB-MMC is controlled at the rated value of $1100 \mathrm{kV}$, Fig. $9(\mathrm{~g})$.

At $t=0.5 \mathrm{~s}$, the power reference of the DFB-MMC is ramped up from 0 to $1 \mathrm{pu}$. Thus, the DC voltage of the FB-MMC starts to increase, as shown in Fig. 9 (f). At $t=0.56 \mathrm{~s}$, the DR starts to conduct and its $\mathrm{AC}$ currents increase for power transmission while the DR DC voltage decreases due to the voltage drop across the leakage reactance of the DR transformer, seen in Fig. 9 (b), (c), (d), (e) and (i). At around $t=0.8 \mathrm{~s}$, the DC voltage of the FB-MMC increases to $148 \mathrm{kV}$ and the transmitted power reaches the rated value of $1200 \mathrm{MW}$ with the grid voltage at the lower limit of 0.9 pu, as observed in Fig. 9 (a), (d) and (f).

2) High grid voltage of $1.1 \mathrm{pu}$

In this scenario, the grid voltage is at the upper limit and the power reference of the DFB-MMC is initially set at the rated value. Due to the high AC grid voltage, the power transmitted via the DR is over the DFB-MMC rated power of $1200 \mathrm{MW}$, seen in Fig. 10 (b). Thus, the FB-MMC outputs negative voltage and operates on inverter mode to export power from the HVDC link to the AC grid and control the DFB-MMC power at the rated, as displayed in Fig. 10 (c), (d) and (f). In such condition, part of the power circulates between the FB-MMC and the diode rectifier, leading to additional losses. However, the circulation power is only a small portion of the total transmitted power (53 MW/1200 MW=4.4\%, as shown in Fig. 10 (c) and (d)) so does not compromise the efficiency of the entire system.

At $t=0.5 \mathrm{~s}$, the power reference of the DFB-MMC is ramped down to 0 in $0.2 \mathrm{~s}$. The DC voltage of the FB-MMC starts to decrease, which leads to the increase of the DR DC voltage, considering the nearly constant HVDC link voltage controlled by the inverter station, as shown in Fig. 10 (e), (f) and (g). The transmitted power of the DR is thus reduced, Fig. 10 (b) and (i). At around $t=0.75 \mathrm{~s}$, the DC voltage of the FB-MMC 
This paper is a post-print of a paper submitted to and accepted for publication in IEEE Journal of Emerging and Selected Topics in Power Electronics and is subject to Institution of Electrical and Electronic Engineering Copyright. The copy of record is available at IEEE Xplore Digital Library.

decreases to around $-148 \mathrm{kV}$ and the $\mathrm{DR}$ becomes reverse blocked. The transmitted power of the DFB-MMC is thus reduced to zero even with the grid voltage at the upper limit of $1.1 \mathrm{pu}$, as observed in Fig. 10 (a), (b), (d) and (f).
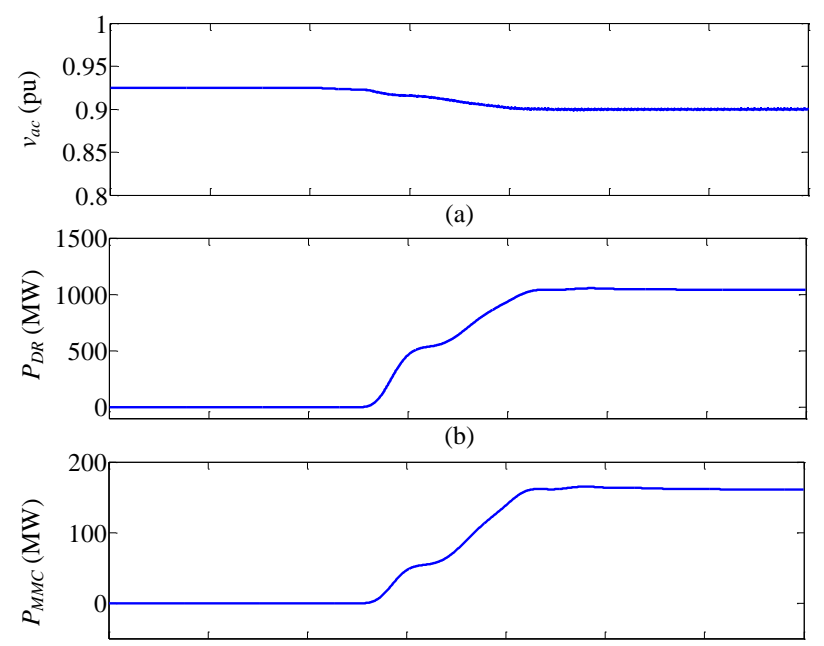

(c)

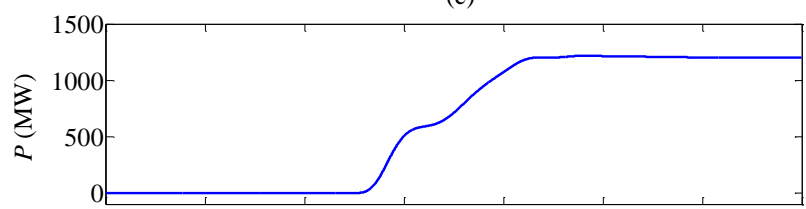

(d)

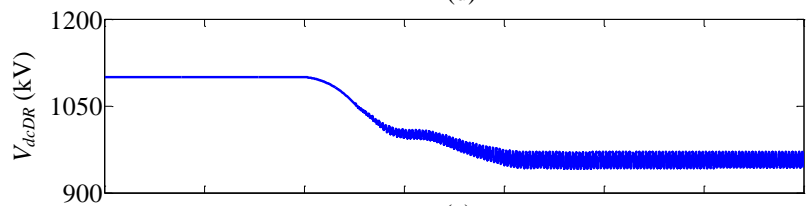

(e)

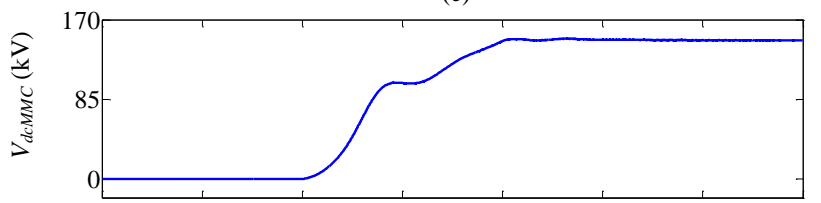

(f)
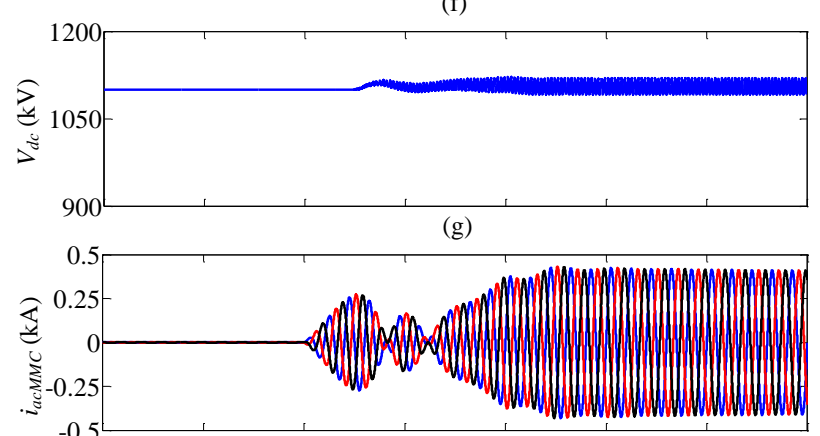

(h)

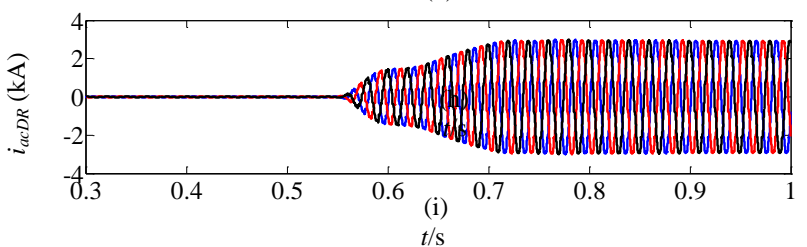

Fig. 9. Waveforms during normal operation with low grid voltage (0.9 pu): (a) grid voltage $v_{a c}$, (b) DR DC power $P_{D R}$, (c) FB-MMC DC power $P_{M M C}$, (d) DFBMMC DC power $P$, (e) DR DC voltage $V_{d c D R}$, (f) FB-MMC DC voltage $V_{d c M M C}$ (g) DFB-MMC DC voltage $V_{d c}$, (h) FB-MMC AC currents $i_{a c M M C}$ and (i) DR AC currents $i_{a c D R}$.

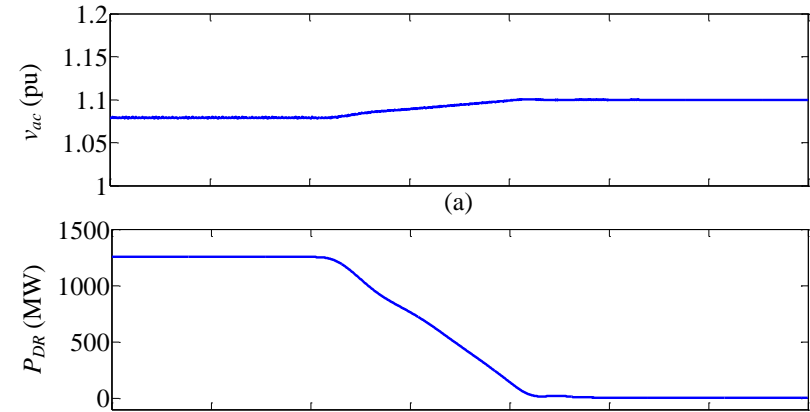

(b)

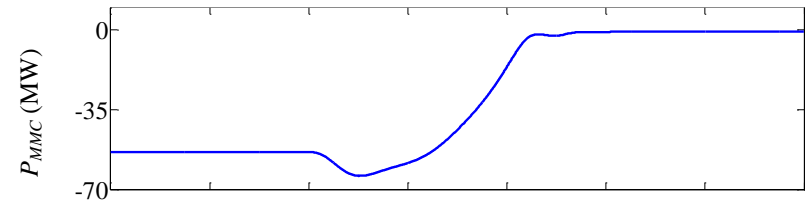

(c)

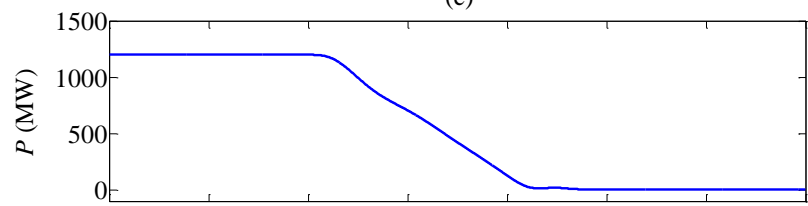

(d)

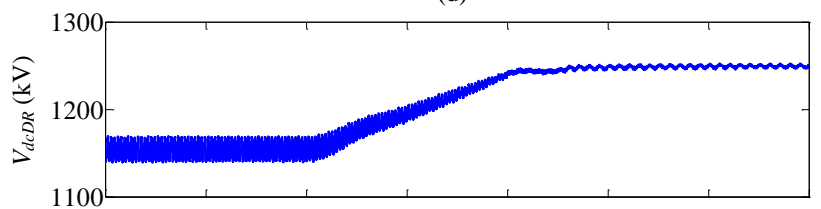

(e)

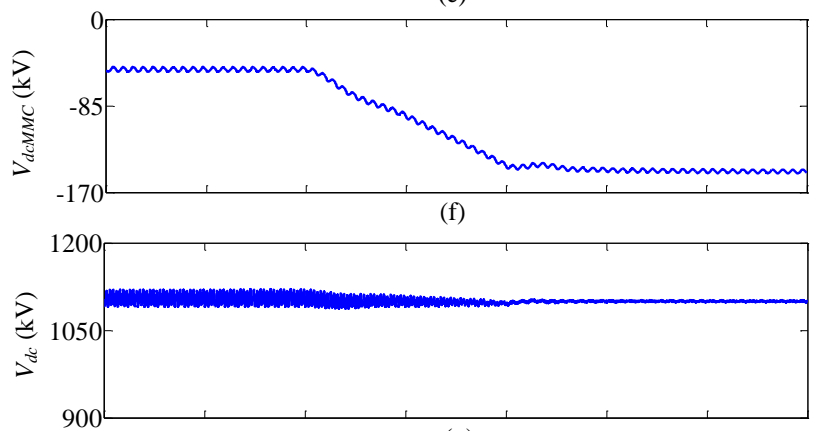

$(\mathrm{g})$

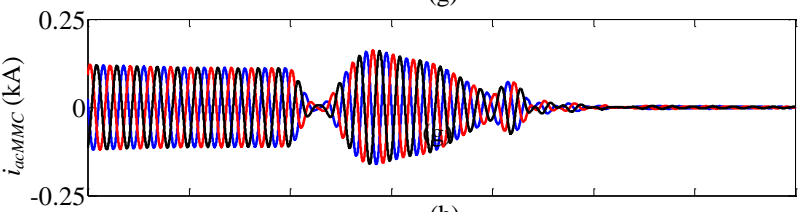

(h)

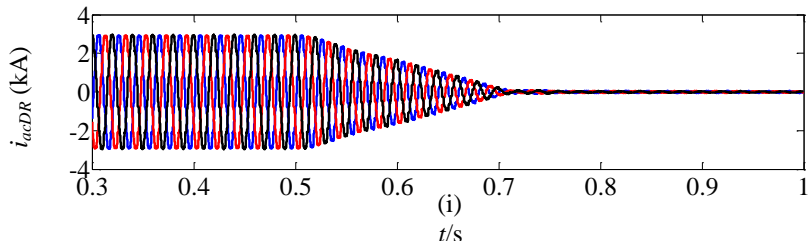

Fig. 10. Waveforms during normal operation with high grid voltage (1.1 pu): (a) grid voltage $v_{a c}$, (b) DR DC power $P_{D R}$, (c) FB-MMC DC power $P_{M M C}$, (d) DFB-MMC DC power $P$, (e) DR DC voltage $V_{d c D R}$, (f) FB-MMC DC voltage $V_{d c M M C}$, (g) DFB-MMC DC voltage $V_{d c}$, (h) FB-MMC AC currents $i_{a c M M C}$ and (i) DR AC currents $i_{a c D R}$.

With the variation of the grid voltage in the range $0.9 \sim 1.1 \mathrm{pu}$, the proposed DFB-MMC is capable of regulating the transmitted power from zero to the rated power, benefiting from 

is subject to Institution of Electrical and Electronic Engineering Copyright. The copy of record is available at IEEE Xplore Digital Library.

the variable DC voltage operating capability of the FB-MMC.

\section{B. DC Faults}

In this scenario, a pole-to-pole permanent DC fault $\mathrm{F} 1$ is applied at the middle of the DC OHLs at $t=1 \mathrm{~s}$, as illustrated in Fig. 3.

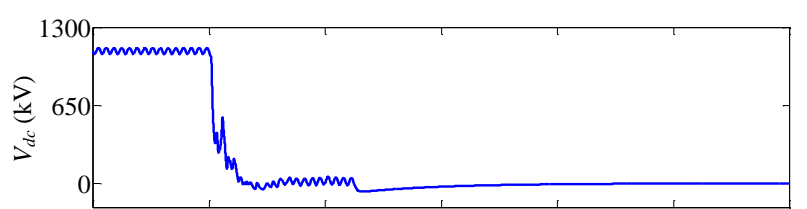

(a)

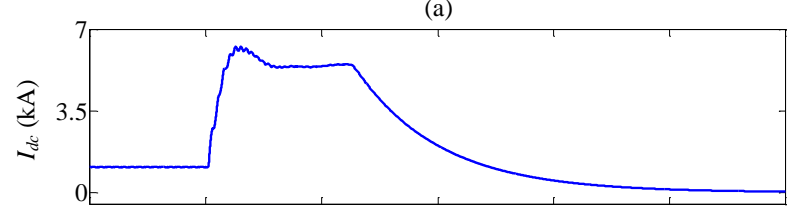

(b)

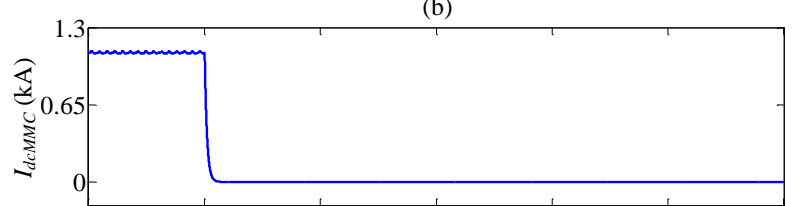

(c)

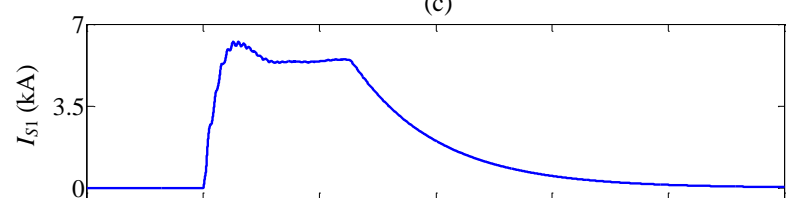

(d)

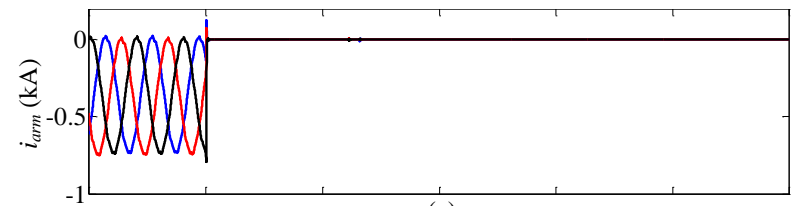

(e)

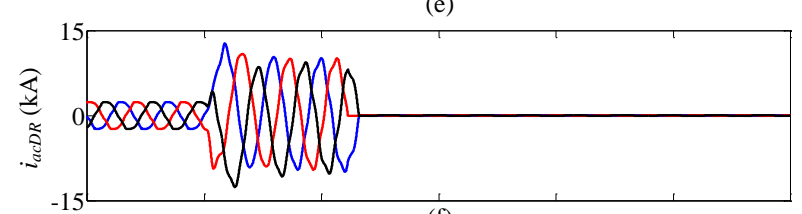

(f)

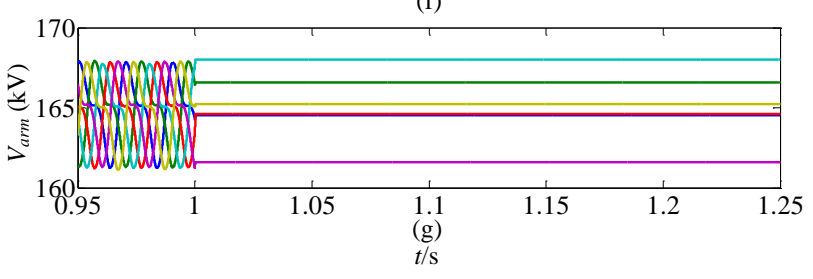

Fig. 11. Waveforms during the DC fault F1: (a) DC voltage $V_{d c}$, (b) DC current $I_{d c}$, (c) FB-MMC DC current $I_{d c M M C}$, (d) thyristor current $I_{S 1}$, (e) FB-MMC arm currents $i_{\text {arm }}$, (f) DR AC currents $i_{a c D R}$ and (g) sum of SM capacitor voltages in each arm of the FB-MMC.

After fault occurrence, the DC voltage of the HVDC link drops to around zero as shown in Fig. 11 (a) and the DFB-MMC is blocked once the fault is detected, while the thyristor valve $S_{1}$ is switched on with $200 \mu$ s delay time. The DC current flowing through the FB-MMC is quickly suppressed to zero following the blocking of the station, as seen in Fig. 11 (c). The fault current from the AC grid through the DR thus only flows through the thyristor valve $S_{1}$ and feeds the fault, as displayed in Fig. 11 (b), (d) and (f). The currents flowing through the converter arms of the FB-MMC are also zero and the FB SMs are not subject to additional thermal stress during DC faults, as seen in Fig. 11 (e). The FB-MMC is effectively bypassed by the thyristor valve $S_{1}$ and thus the capacitor voltages of the FB SMs do not have over charging issue, as demonstrated in Fig. 11 (g).
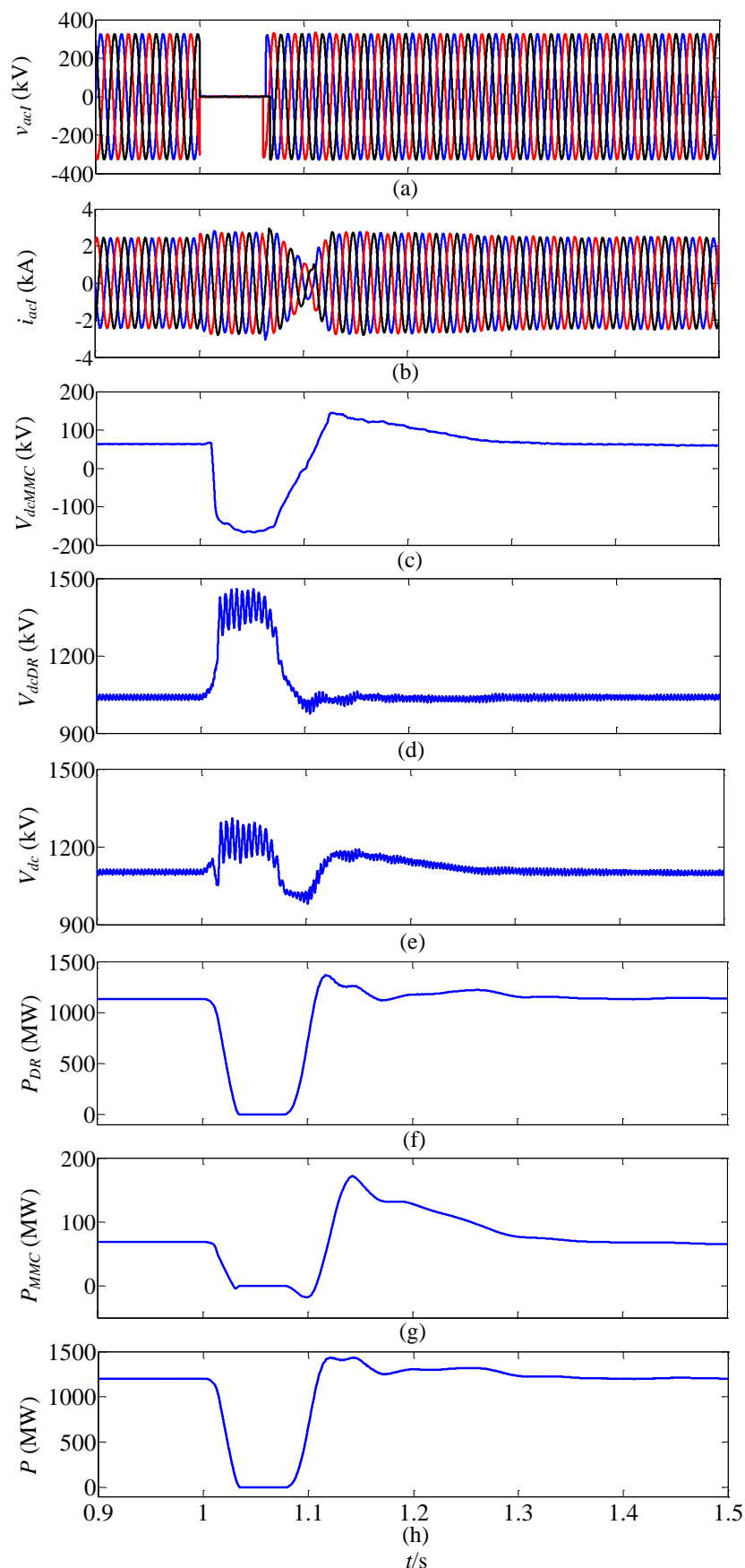

Fig. 12. Waveforms during the $\mathrm{AC}$ fault $\mathrm{F} 2$ at the $\mathrm{AC}$ grid of the inverter station: (a) inverter station $\mathrm{AC}$ voltages $v_{a c}$, (b) inverter station AC currents $i_{a c l}$, (c) FB-MMC DC voltage $V_{d c M M C}$, (d) DR DC voltage $V_{d c D R}$, (e) DFB-MMC DC voltage $V_{d c}$, (f) DR DC power $P_{D R}$, (g) FB-MMC DC power $P_{M M C}$ and (h) DFBMMC DC power $P$.

At $t=1.061 \mathrm{~s}$, the AC circuit breaker on the DFB-MMC AC side opens and the AC currents flowing through the DR drop to zero, seen in Fig. 11 (f). As observed in Fig. 11 (b) and (d), the fault currents on DC side gradually decay, depending on the resistance and inductance of the fault current path. As shown in 

is subject to Institution of Electrical and Electronic Engineering Copyright. The copy of record is available at IEEE Xplore Digital Library.

Fig. 11 (d), the peak fault current flowing through the thyristor valve $S_{1}$ is around $6.2 \mathrm{kA}$ and is in the safe operation range of typical high power thyristors $[45,46]$. It is equivalent to $5.7 \mathrm{pu}$ $(6.2 \mathrm{kA} / 1.09 \mathrm{kA})$, which is in the similar range to that in [47, $48]$.

\section{Inverter Station AC Faults}

To test the proposed topology and control in the event of an AC grid fault of the inverter station, a symmetrical solid fault F2 is applied at the AC side of the HB-MMC of the inverter station as illustrated in Fig. 3 at $t=1 \mathrm{~s}$ and is cleared after $60 \mathrm{~ms}$.

As shown in Fig. 12 (a) and (b), the grid voltage of the inverter station drops to zero after fault occurrence and the inverter HB-MMC operates on current limiting mode to support the AC grid. As the output power of the HB-MMC is reduced to zero and the rectifier station DFB-MMC still imports energy to HVDC-link, the DC voltage increases. Once the DC voltage reaches $1.05 \mathrm{pu}$, the proposed dynamic DC voltage limiter is activated to actively reduce the DC voltage of the FB-MMC and the transmitted power is quickly suppressed to zero, as displayed in Fig. 12 (c), (f), (g) and (h). This effectively reduces the DC overvoltage of the HVDC link, as shown in Fig. 12 (e).

After fault clearance $t=1.06 \mathrm{~s}$, the power transmission of the inverter HB-MMC resumes and the system autonomously restores normal operation without communication.

\section{CONCLUSION}

A unidirectional hybrid HVDC converter composed of diode rectifier and FB-MMC is proposed, where the FB-MMC operates with variable $\mathrm{DC}$ voltage to regulate the transmitted power. The thyristor connected at the DC terminal of the FBMMC is switched on during DC faults to bypass the FB-MMC so as to avoid overcharge of the FB SMs. The major power is transferred through the DR and only low power rating FBMMC is required. Compared to the conventional MMC, the losses of the proposed converter are reduced by around $20 \%$. The proposed active power controller regulates the DC voltage of the FB-MMC to control the transmitted power. The FBMMC increases the output DC voltage to increase the transmitted power and, vice versa. During AC grid faults of the inverter station, the FB-MMC outputs negative DC voltage with the proposed dynamic DC voltage limiter to effectively alleviate overvoltage of the HVDC link. The proposed topology achieves good balance between efficiency and controllability and provides a promising solution for the bulk energy transmission.

\section{REFERENCES}

[1] J. Hu, Z. He, L. Lin, K. Xu, and Y. Qiu, "Voltage Polarity Reversing-Based DC Short Circuit FRT Strategy for Symmetrical Bipolar FBSM-MMC HVDC System," IEEE Journal of Emerging and Selected Topics in Power Electronics, vol. 6, pp. 1008-1020, 2018.

[2] G. Liu, F. Xu, Z. Xu, Z. Zhang, and G. Tang, "Assembly HVDC Breaker for HVDC Grids With Modular Multilevel Converters," IEEE Transactions on Power Electronics, vol. 32, pp. 931-941, 2017.

[3] R. Zeng, L. Xu, L. Yao, and B. W. Williams, "Design and Operation of a Hybrid Modular Multilevel Converter," Power Electronics, IEEE Transactions on, vol. 30, pp. 1137-1146, 2015.
[4] M. M. C. Merlin, D. Soto-Sanchez, P. D. Judge, G. Chaffey, P. Clemow, T. C. Green, et al., "The Extended Overlap Alternate Arm Converter: A Voltage-Source Converter With DC Fault Ride-Through Capability and a Compact Design," IEEE Transactions on Power Electronics, vol. 33, pp. 3898-3910, 2018.

[5] R. Li, G. P. Adam, D. Holliday, J. E. Fletcher, and B. W. Williams, "Hybrid Cascaded Modular Multilevel Converter With DC Fault Ride-Through Capability for the HVDC Transmission System," Power Delivery, IEEE Transactions on, vol. 30, pp. 1853-1862, 2015.

[6] O. Kuhn, P. Menke, R. Zurowski, T. Christ, S. Seman, G. Giering, et al., "2nd generation DC grid access for offshore wind farms: HVDC in an AC fashion," CIGRE, Paris, pp. 1-7, 2016.

[7] S. Seman, R. Zurowski, and C. Taratoris, "Interconnection of advanced Type 4 WTGs with Diode Rectifier based HVDC solution and weak AC grids," in Proceedings of the 14th Wind Integration Workshop,Brussels, Belgium, 20th-22nd Oct. , 2015.

[8] T. H. Nguyen, D. C. Lee, and C. K. Kim, "A Series-Connected Topology of a Diode Rectifier and a Voltage-Source Converter for an HVDC Transmission System," IEEE Trans. Power Electron., vol. 29, pp. 15791584,2014

[9] R. Blasco-Gimenez, S. A.-. Villalba, J. Rodríguez-D'Derlée, F. Morant, and S. Bernal-Perez, "Distributed Voltage and Frequency Control of Offshore Wind Farms Connected With a Diode-Based HVdc Link," IEEE Transactions on Power Electronics, vol. 25, pp. 3095-3105, 2010.

[10]S. Bernal-Perez, S. Ano-Villalba, R. Blasco-Gimenez, and J. RodriguezD'Derlee, "Efficiency and Fault Ride-Through Performance of a DiodeRectifier- and VSC-Inverter-Based HVDC Link for Offshore Wind Farms," IEEE Transactions on Industrial Electronics, vol. 60, pp. 24012409, 2013.

[11]R. Blasco-Gimenez, S. Anó-Villalba, J. Rodriguez-D'Derlée, S. BernalPerez, and F. Morant, "Diode-Based HVdc Link for the Connection of Large Offshore Wind Farms," IEEE Transactions on Energy Conversion, vol. 26, pp. 615-626, 2011.

[12]L. Yu, R. Li, and L. Xu, "Distributed PLL-Based Control of Offshore Wind Turbines Connected With Diode-Rectifier-Based HVDC Systems," IEEE Transactions on Power Delivery, vol. 33, pp. 1328-1336, 2018.

[13]R. Li, L. Yu, and L. Xu, "Offshore AC Fault Protection of Diode Rectifier Unit Based HVDC System for Wind Energy Transmission," IEEE Transactions on Industrial Electronics, pp. 1-1, 2018.

[14]T. H. Nguyen, D.-C. Lee, and C.-K. J. I. T. o. P. E. Kim, "A seriesconnected topology of a diode rectifier and a voltage-source converter for an HVDC transmission system," vol. 29, pp. 1579-1584, 2013.

[15]A. Nami, J. L. Rodriguez-Amenedo, S. Arnaltes, M. Á. Cardiel-Álvarez, and R. A. Baraciarte, "Frequency Control of Offshore Wind Farm With Diode-Rectifier-based HVdc Connection," IEEE Transactions on Energy Conversion, vol. 35, pp. 130-138, 2020.

[16]R. Li, L. Yu, L. Xu, and G. P. Adam, "Coordinated Control of Parallel DRHVDC and MMC-HVDC Systems for Offshore Wind Energy Transmission," IEEE Journal of Emerging and Selected Topics in Power Electronics, pp. 1-1, 2019.

[17]A. Nami, J. L. Rodríguez-Amenedo, S. Arnaltes, M. Á. C. Álvarez, and R. A. Baraciarte, "Hybrid HVDC System for Offshore Wind Farms Connection Using Series-connected Diode Rectifier Units," in 201921 st European Conference on Power Electronics and Applications (EPE '19 ECCE Europe), 2019, pp. P.1-P.10.

[18] Y. Chang and X. Cai, "Hybrid Topology of a Diode-Rectifier-based HVDC System for Offshore Wind Farms," IEEE Journal of Emerging and Selected Topics in Power Electronics, pp. 1-1, 2018.

[19]G. Tang, Z. Xu, and Y. Zhou, "Impacts of Three MMC-HVDC Configurations on AC System Stability Under DC Line Faults," IEEE Transactions on Power Systems, vol. 29, pp. 3030-3040, 2014

[20]S. Howell, S. Filizadeh, and A. M. Gole, "Unidirectional HVdc Topology With DC Fault Ride-Through Capability," Canadian Journal of Electrical and Computer Engineering, vol. 40, pp. 41-49, 2017.

[21]T. Kawaguchi, T. Sakazaki, T. Isobe, and R. Shimada, "Offshore-WindFarm Configuration Using Diode Rectifier With MERS in Current Link Topology," IEEE Transactions on Industrial Electronics, vol. 60, pp. 29302937, 2013

[22]R. Li, L. Xu, D. Holliday, F. Page, S. J. Finney, and B. W. Williams, "Continuous Operation of Radial Multiterminal HVDC Systems Under DC Fault," IEEE Transactions on Power Delivery, vol. 31, pp. 351-361, 2016.

[23] N. M. Haleem, A. D. Rajapakse, A. M. Gole, and I. T. Fernando, "Investigation of Fault Ride-Through Capability of Hybrid VSC-LCC Multi-Terminal HVDC Transmission Systems," IEEE Transactions on Power Delivery, vol. 34, pp. 241-250, 2019. 
This paper is a post-print of a paper submitted to and accepted for publication in IEEE Journal of Emerging and Selected Topics in Power Electronics and is subject to Institution of Electrical and Electronic Engineering Copyright. The copy of record is available at IEEE Xplore Digital Library.

[24]H. Wang and K. Ma, "IGBT technology for future high-power VSC-HVDC applications," in 12th IET International Conference on AC and DC Power Transmission (ACDC 2016), 2016, pp. 1-6.

[25]G. Xiguo, "A 3.3kV IGBT module and application in modular multilevel converter for HVDC," in 2012 IEEE International Symposium on Industrial Electronics, 2012, pp. 1944-1949.

[26] B. Jacobson, P. Karlsson, G. Asplund, L. Harnefors, and T. Jonsson, "VSCHVDC transmission with cascaded two-level converters," in Cigré session, 2010, pp. B4-B110.

[27] R. Li and J. E. Fletcher, "A novel MMC control scheme to increase the DC voltage in HVDC transmission systems," Electric Power Systems Research, vol. 143, pp. 544-553, 2// 2017.

[28] ABB, It's time to connect, 2017.

[29]T. Jonsson, P. Lundberg, S. Maiti, and Y. Jiang-Häfner, "Converter technologies and functional requirements for reliable and economical HVDC grid design," Cigre Canada, Calgary, Canada, 2013.

[30]Q. Song, R. Zeng, Z. Yu, W. Liu, Y. Huang, W. Yang, et al., "A Modular Multilevel Converter Integrated With DC Circuit Breaker," IEEE Transactions on Power Delivery, vol. 33, pp. 2502-2512, 2018.

[31]P. S. Jones and C. C. Davidson, "Calculation of power losses for MMCbased VSC HVDC stations," in 2013 15th European Conference on Power Electronics and Applications (EPE), 2013, pp. 1-10.

[32] S. Bernal-Perez, S. Ano-Villalba, R. Blasco-Gimenez, and J. RodriguezD'Derlee, "Efficiency and Fault Ride-Through Performance of a DiodeRectifier- and VSC-Inverter-Based HVDC Link for Offshore Wind Farms," Industrial Electronics, IEEE Transactions on, vol. 60, pp. 24012409, 2013.

[33] Y. Xue, X. Zhang, and C. Yang, "Series Capacitor Compensated AC Filterless Flexible LCC HVDC With Enhanced Power Transfer Under Unbalanced Faults," IEEE Transactions on Power Systems, vol. 34, pp. 3069-3080, 2019.

[34] R. Li, L. Xu, L. Yu, and L. Yao, "A Hybrid Modular Multilevel Converter with Reduced Full-Bridge Submodules," IEEE Transactions on Power Delivery, pp. 1-1, 2019.

[35]R. Blasco-Gimenez, N. Aparicio, S. Ano-Villalba, and S. Bernal-Perez, "LCC-HVDC Connection of Offshore Wind Farms With Reduced Filter Banks," IEEE Transactions on Industrial Electronics, vol. 60, pp. 2372 2380, 2013.

[36]M. A. Cardiel-Alvarez, J. L. Rodriguez-Amenedo, S. Arnaltes, and M. Montilla-DJesus, "Modeling and Control of LCC Rectifiers for Offshore Wind Farms Connected by HVDC Links," IEEE Transactions on Energy Conversion, vol. PP, pp. 1-1, 2017.

[37] J. Rafferty, X. Lie, and J. Morrow, "Analysis of voltage source converterbased high-voltage direct current under DC line-to-earth fault," Power Electronics, IET, vol. 8, pp. 428-438, 2015.

[38]T. Lianxiang and O. Boon-Teck, "Managing zero sequence in voltage source converter," in Industry Applications Conference, 2002. 37th IAS Annual Meeting. Conference Record of the, 2002, pp. 795-802 vol.2.

[39] Y. Jin, J. E. Fletcher, and J. O'Reilly, "Short-Circuit and Ground Fault Analyses and Location in VSC-Based DC Network Cables," Industrial Electronics, IEEE Transactions on, vol. 59, pp. 3827-3837, 2012.

[40]T. K. Vrana, Y. Yang, D. Jovcic, S. Dennetière, J. Jardini, and H. Saad, "The CIGRE B4 DC grid test system," Electra, vol. 270, pp. 10-19, 2013.

[41]H. Pang and X. Wei, "Research on Key Technology and Equipment for Zhangbei 500kV DC Grid," in 2018 International Power Electronics Conference (IPEC-Niigata 2018 -ECCE Asia), 2018, pp. 2343-2351.

[42]M.-S. Kang, J.-I. Tsai, R.-C. Wu, and J.-D. Wu, "Depressing Torisonal Torques in Turbine-Generators Using Petersen Coil Scheme Subject to Single-Phase to Ground Faults," GEN, vol. 1, p. 0.00012, 2007.

[43] S. Tasnim, A. Rahman, A. M. T. Oo, and M. F. Islam, "Power losses from wind generated electricity in high voltage AC transmission: an analysis through simulation," International Journal of Renewable Energy Technology, vol. 5, pp. 77-92, 2014.

[44]R. Li, L. Xu, and D. Guo, "Accelerated switching function model of hybrid MMCs for HVDC system simulation," IET Power Electronics, 2017.

[45] K. Tahata, S. Ka, S. Tokoyoda, K. Kamei, K. Kikuchi, D. Yoshida, et al., "HVDC circuit breakers for HVDC grid applications," in Proc. Cigré AORC Technical Meeting, Tokyo, Japan, 2014.

[46]L. Ängquist, A. Baudoin, S. Norrga, S. Nee, and T. Modeer, "Low-cost ultra-fast DC circuit-breaker: Power electronics integrated with mechanical switchgear," in 2018 IEEE International Conference on Industrial Technology (ICIT), 2018, pp. 1708-1713.

[47] J. Peralta, H. Saad, S. Dennetiere, J. Mahseredjian, and S. Nguefeu, "Detailed and Averaged Models for a 401-Level MMC\&\#x2013;HVDC
System," IEEE Transactions on Power Delivery, vol. 27, pp. 1501-1508, 2012.

[48]R. Li, J. E. Fletcher, L. Xu, D. Holliday, and B. W. Williams, "A Hybrid Modular Multilevel Converter With Novel Three-Level Cells for DC Fault Blocking Capability," Power Delivery, IEEE Transactions on, vol. 30, pp. 2017-2026, 2015

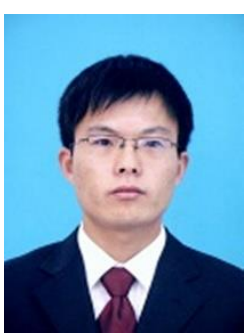

Rui Li (M'18) received the M.S. and Ph.D degrees in electrical engineering from Harbin Institute of Technology, Harbin, China, in 2008 and 2013, respectively. He is a researcher with University of Strathclyde in Glasgow, UK, since 2013.

His research interests include HVDC transmision systems, grid integration of renewable power, power electronic converters, and energy conversion.

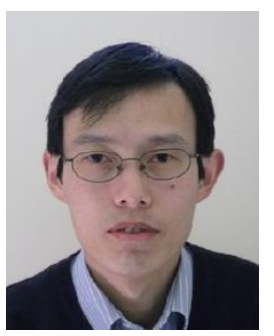

Lie Xu (M'03-SM'06) received the B.Sc. degree in Mechatronics from Zhejiang University, Hangzhou, China, in 1993, and the Ph.D. degree in Electrical Engineering from the University of Sheffield, Sheffield, UK, in 2000.

$\mathrm{He}$ is currently a Professor at the Department of Electronic \& Electrical Engineering, University of Strathclyde, Glasgow, UK. He previously worked in Queen's University of Belfast and ALSTOM T\&D, Stafford, UK. His current research interests include power electronics, wind energy generation and grid integration, and application of power electronics to power systems. He is an Editor of IEEE Transactions on Power Delivery and IEEE Transactions on Energy Conversion. 